\title{
Mice Haploinsufficient for Ets1 and Fli1 Display Middle Ear Abnormalities and Model Aspects of Jacobsen Syndrome
}

\author{
Marina R. Carpinelli, ${ }^{* \dagger}$ Elizabeth A. Kruse, ${ }^{\ddagger \S}$ Benedicta D. Arhatari, ${ }^{\natural}$ Marlyse A. Debrincat, ${ }^{\ddagger \S}$ Jacqueline M. Ogier, ${ }^{* \dagger}$
} Jean-Christophe Bories, Benjamin T. Kile, ${ }^{\ddagger \S}$ and Rachel A. Burt* ${ }^{* \neq * *}$

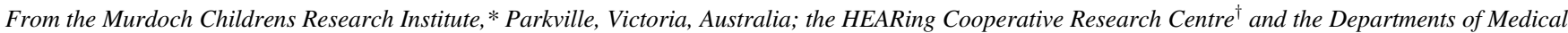
Biology ${ }^{\S}$ and Genetics, ** University of Melbourne, Melbourne, Victoria, Australia; the Walter and Eliza Hall Institute of Medical Research, ${ }^{\ddagger}$ Parkville, Victoria, Australia; the Department of Physics, ${ }^{\top}$ ARC Centre of Excellence for Coherent X-Ray Science, La Trobe University, Bundoora, Victoria, Australia; and INSERM UMR 1126 Institut Universitaire d'Hématologie, "Paris, France
\end{abstract}

Accepted for publication

March 2, 2015.

Address correspondence to Rachel A. Burt, Ph.D., Murdoch Childrens Research Institute, 50 Flemington Rd, Parkville, VIC 3052, Australia. E-mail: rachel.burt@mcri. edu.au.

\begin{abstract}
E26 transformation-specific 1 (ETS1) and friend leukemia integration 1 (FLI1) are members of the ETS family of transcription factors, of which there are 28 in humans. Both genes are hemizygous in Jacobsen syndrome, an 11q contiguous gene deletion disorder involving thrombocytopenia, facial dysmorphism, growth and mental retardation, malformation of the heart and other organs, and hearing impairment associated with recurrent ear infections. To determine whether any of these defects are because of hemizygosity for ETS1 and FLI1, we characterized the phenotype of mice heterozygous for mutant alleles of Ets1 and Fli1. Fli1 ${ }^{+/-}$mice displayed mild thrombocytopenia, as did $\mathrm{Ets}^{+/-} \mathrm{Fli1}^{+/-}$animals. Fli1 ${ }^{+/-}$ and $E t s 1^{+/-}$Fli1 $^{+/-}$mice also displayed craniofacial abnormalities, including a small middle ear cavity, short nasal bone, and malformed interface between the nasal bone process and cartilaginous nasal septum. They exhibited hearing impairment, otitis media, fusions of ossicles to the middle ear wall, and deformed stapes. Hearing impairment was more penetrant and stapes malformations were more severe in Ets ${ }^{+/-} \mathrm{Fli}^{+/-}$mice than in $\mathrm{Fli} 1^{+/-}$mice, indicating partial functional redundancy of these transcription factors during auditory development. Our findings indicate that the short nose, otitis media, and hearing impairment in Jacobsen syndrome are likely because of hemizygosity for ETS1 and FLI1. (Am J Pathol 2015, 185: 1867-1876; http://dx.doi.org/10.1016/j.ajpath.2015.03.026)
\end{abstract}

Jacobsen syndrome (JS) is a dominant, polygenic disorder caused by partial deletion of the long arm of chromosome 11. ${ }^{1}$ Estimated occurrence is 1 in 100,000 births, and clinical features include facial dysmorphism, thrombocytopenia and platelet dysfunction, malformation of the heart and other organs, growth and psychomotor retardation, and hearing impairment. ${ }^{1}$ Thrombocytopenia in JS and the related ParisTrousseau syndrome is associated with bone marrow dysmegakaryopoiesis, high platelet volume, and giant $\alpha$ granules in platelets. ${ }^{2,3}$ The hearing impairment is associated with recurrent/chronic middle ear inflammation (otitis media). ${ }^{4} \mathrm{JS}$ deletions have a breakpoint at or telomeric to $11 \mathrm{q} 23.3$, and the approximately $14-\mathrm{Mb}$ minimal deleted region for expressing the JS phenotype includes 174 genes. ${ }^{1}$ Some correlations between the clinical phenotype and extent of the deletion have been observed, ${ }^{4}$ but few of the genes responsible for specific aspects of JS have been identified.

The 28 human E26 transformation-specific (ETS) transcription factors contain a winged helix-turn-helix DNA

\footnotetext{
Supported by the HEARing Cooperative Research Centre, established and supported under the Cooperative Research Centers Program, an Australian Government Initiative; the Garnett Passe and Rodney Williams Memorial Foundation (M.R.C.); the Australian Government's National Health and Medical Research Council program grants 461219 and 1016647 (B.T.K.) and independent research institutes infrastructure support scheme grant 361646; the Sylvia and Charles Viertel foundation (B.T.K.); and the Victorian State Government's operational infrastructure support program.

Disclosures: None declared.

Current address of M.R.C., The Alfred, Prahran, VIC, Australia; of E.A.K., Stem Cell Laboratory, University College London, London, UK.
} 
binding domain that recognizes a $5^{\prime}-\mathrm{GGA}(\mathrm{A} / \mathrm{T})-3^{\prime}$ motif. ${ }^{5}$ ETS1 was identified as the cellular homolog of an oncogene from avian erythroblastosis virus. ${ }^{6-8}$ Friend leukemia integration 1 (Flil) was identified as the site of viral integration in mouse erythroleukemia. ${ }^{9,10}$ ETS1 and FLII are located $<100$ $\mathrm{kb}$ apart on chromosome 11 (GRCh38) and are from different subfamilies within the ETS gene family. ${ }^{5}$ The orthologous murine genes, Flil and Etsl, encode proteins sharing 30\% amino acid identity ${ }^{10}$ and have similar patterns of expression, beginning soon after gastrulation. ${ }^{11,12}$ At embryonic day 8 (e8), Fli1 is expressed in migrating neural crest and in mesenchymal cells of the cephalic region derived from the neural crest. $^{12}$ At e9, Etsl is expressed in mesencephalic neural crest cells and at e10 to e15 in mesenchymal cells of developing organs. ${ }^{11}$

Insights into the functions of Flil and Ets 1 have been obtained via the study of mice carrying mutant alleles. $\mathrm{Fli1}^{-/}$ animals die at e11.5 of intracranial hemorrhage. ${ }^{13}$ Their fetal livers contain an abnormally high number of megakaryocyte progenitors, and these form colonies with an immature phenotype in vitro. ${ }^{13} \mathrm{Flil}^{+/-}$megakaryocytes have a disorganized demarcation membrane system, vacuolization, and fused $\alpha$-granules. ${ }^{14}$ In Paris-Trousseau syndrome, hemizygous loss of FLII causes dysmegakaryopoiesis, with transient low or monoallelic expression of FLII in megakaryocyte progenitors proposed as the mechanism leading to haploinsufficiency. ${ }^{15}$ Thus, Fli1 has important roles in both vascular development and platelet production by megakaryocytes.

$E t s 1^{-/-}$mice display an abnormally high rate of perinatal mortality, and 50\% survive to 4 weeks of age. ${ }^{16}$ Adult Ets ${ }^{-1-}$ mice are viable and fertile and have normal numbers of platelets but few natural killer cells and abnormal $\mathrm{T}$ and $\mathrm{B}$ lymphocytes. ${ }^{16,17}$ Ets $1^{-/-}$mice display large membranous ventricular septal heart defects at e15.5 to e17.5, ${ }^{18}$ indicating that the congenital heart defects in JS may be because of hemizygosity for ETS1. Thus, Etsl has important roles in heart development, natural killer cells, and $\mathrm{B}$ and $\mathrm{T}$ lymphocytes.

In the course of studying mice with mutations in Flil and the closely related ETS family transcription factor, $\mathrm{Erg},{ }^{14}$ we noticed that animals heterozygous for mutations in both genes exhibited craniofacial abnormalities (data not shown). This led us to speculate that ETS transcription factors might play a broader role in craniofacial development than currently appreciated. Given the link between FLII and JS, and its close physical proximity to ETS1 on chromosome 11, we hypothesized that combined haploinsufficiency for ETS1 and FLII might underpin some features of JS, particularly the craniofacial abnormalities. We, therefore, elected to generate and characterize animals heterozygous for a null allele of Etsl and a severely hypomorphic allele of Flil. These mice displayed a short nasal bone and malformed nasal septum, small middle ear cavity (MEC), otitis media, malformed stapes, and hearing impairment. This indicates that the hearing impairment, otitis media, and short nasal bone in JS patients are likely because of haploinsufficiency for ETS1 and FLII.

\section{Materials and Methods}

\section{Mice}

Mice were bred and maintained at the Walter and Eliza Hall Institute of Medical Research (Parkville, VIC, Australia). Animals were group housed in microisolator cages on a 12hour light-dark cycle. The Ets $I^{\text {tm IFwa19 }}$ and the Fli $1^{\text {tm 1.1Dkw }}$ mouse strains ${ }^{20}$ have been backcrossed at least 10 times to C57BL/6J. Fli $1^{\text {tm 1.1Dkw }}$ is a severe hypomorphic allele that causes a phenotype similar to the null allele, Fli ${ }^{\text {tmlAdh }}{ }^{13,20}$ and is referred to as $\mathrm{Flil}^{-}$herein. Experimental cohorts of mice were generated by Ets ${ }^{+/-} \times \mathrm{Flil}^{+/-}$crosses. Animal experiments were approved by the Walter and Eliza Hall Institute animal ethics committee and conformed to the Australian Code of Practice for the Care and Use of Animals for Scientific Purposes, edition 8, 2013.

\section{Genotyping}

The Ets 1 locus was genotyped by PCR using common primer 5'-TCTGAAGTCTTGACCCAGCTATCCTG-3' with either wild-type-specific primer $5^{\prime}$-GAGAGACTCACTGAGAAGCCATTC-3' or mutant-specific primer 5'-GCGCATGCTCCAGACTGCCTTG- $3^{\prime}$. Reactions $(25 \mu \mathrm{L})$ contained genomic DNA, $0.5 \mu \mathrm{mol} / \mathrm{L}$ each primer, $1 \times$ CoralLoad PCR buffer, $0.5 \times \mathrm{Q}$ solution, $0.5 \mu \mathrm{mol} / \mathrm{L} \mathrm{MgCl}_{2}, 2 \mu \mathrm{mol} / \mathrm{L} \mathrm{dNTPs}$, and 2.5 U Taq DNA polymerase (all from Qiagen, Chadstone, VIC, Australia). Separate reactions were performed for the wild-type and mutant alleles. Reactions were subjected to an initial denaturation of $94^{\circ} \mathrm{C}$ for 5 minutes, followed by 35 cycles at $94^{\circ} \mathrm{C}$ for 1 minute, $56^{\circ} \mathrm{C}$ for 1 minute, and $72^{\circ} \mathrm{C}$ for 1 minute, with a final extension of $72^{\circ} \mathrm{C}$ for 10 minutes. PCR product sizes were $450 \mathrm{bp}$ for the wild-type allele and $350 \mathrm{bp}$ for the mutant allele.

Genotyping of Flil was performed by PCR with the common primer 5'-GACCAACGGGGAGTTCAAAATGACG-3', wild-type-specific primer $5^{\prime}$-GGAGGATGGGTGAGACGGGACAAAG-3' ${ }^{\prime}$, and mutant-specific primer 5'-GGAAGTAGCCGTTATTAGTGGAGAGG-3' all in one reaction. Reaction conditions were as above, with the exception that PCR cycles were $94^{\circ} \mathrm{C}$ for 3 minutes, followed by 35 cycles of $94^{\circ} \mathrm{C}$ for 30 seconds, $60^{\circ} \mathrm{C}$ for 30 seconds, and $72^{\circ} \mathrm{C}$ for 30 seconds, followed by a final extension of $72^{\circ} \mathrm{C}$ for 7 minutes. Product sizes were $309 \mathrm{bp}$ for the wild-type allele and $406 \mathrm{bp}$ for the mutant allele.

\section{ABR Data}

Mice were auditory brainstem response (ABR) tested at 8 to 10 weeks of age. Although C57BL/6 mice harbor a $C d h 23$ mutation that causes age-related hearing loss, ${ }^{21}$ significant impairment does not occur before 27 to 33 weeks of age, ${ }^{22}$ and in our hands, 8- to 10-week-old C57BL/6 mice from the WEHI colony do not display elevated ABR thresholds. ABRs were measured as described previously. ${ }^{23,24}$ Briefly, 
mice were anesthetized by i.p. injection of $100 \mathrm{mg} / \mathrm{kg}$ ketamine and $20 \mathrm{mg} / \mathrm{kg}$ xylazine, and their eyes were moistened with Lacri-Lube (Allergan, Parsippany, NJ). Body temperature was maintained with a $37^{\circ} \mathrm{C}$ heat pad. A custom-made faraday chamber was placed inside a Habitest isolation cubicle (model H10-24A; Coulbourn Instruments, Whitehall, PA). A free-field magnetic speaker (model FF1; Tucker Davis Technologies, Alachua, FL) was placed $10 \mathrm{~cm}$ from the left pinna. Computergenerated clicks (100-microsecond duration, with a spectrum of 0 to $50 \mathrm{kHz}$ ) and 3-millisecond pure-tone stimuli of 4, 8, 16, and $32 \mathrm{kHz}$ were presented with maximum intensities of 100$\mathrm{dB}$ sound pressure level (SPL). ABRs were recorded differentially using subdermal needle electrodes (S06666-0; Rochester Electro-Medical, Inc., Lutz, FL) positioned at the vertex of the skull $(+\mathrm{ve})$, left cheek $(-\mathrm{ve})$, and hind leg (ground). ABRs were averaged over 512 repetitions of the stimulus using BioSig software (Tucker Davis Technologies). The ABR threshold was defined as the lowest intensity stimulus that reproducibly elicited a wave III ABR.

\section{Histological Data}

Cochlear and middle ear histological data were collected as described previously. ${ }^{25,26}$ Briefly, 8- to 10 -week-old mice were euthanized by i.p. injection of $400 \mathrm{mg} / \mathrm{kg}$ ketamine and $80 \mathrm{mg} / \mathrm{kg}$ xylazine. The right atrium was incised, and phosphate-buffered saline was perfused via a cannula inserted into the left ventricle for 5 minutes, followed by $10 \%$ neutralbuffered formalin for 5 minutes. Bullae were dissected and fixed for 1 hour, washed in Tris-buffered saline, and decalcified in 10\% EDTA in phosphate-buffered saline for 5 days at $4^{\circ} \mathrm{C}$. Bullae were paraffin embedded, and sections ( $2 \mu \mathrm{m}$ thick) were cut using a microtome. Sternums of perfused mice were fixed in $10 \%$ neutral-buffered formalin for 1 day, decalcified in Fronine fastcal decalcifying solution (Thermo Fisher Scientific, Taren Point, NSW, Australia) for 2 to 3 hours, and embedded in paraffin before dividing into sections. Coronal sections of the head were obtained from the Australian Phenomics Network Histopathology and Organ Pathology Service (Parkville, VIC, Australia). All sections were stained with hematoxylin and eosin and imaged with a DM1000 compound microscope (Leica Microsystems, North Ryde, NSW, Australia) and a DFC450 C camera (Leica Microsystems).

\section{X-Ray Microcomputed Tomography}

$\mathrm{X}$-ray microcomputed tomography was conducted using an Xradia machine MicroXCT-200 (Xradia Inc., Pleasanton, CA). An X-ray closed-tube source with a Tungsten target was operated at $60 \mathrm{kV}$ tube voltage and power of $10 \mathrm{~W}$. The sample was placed at $120 \mathrm{~mm}$ from the source and $20 \mathrm{~mm}$ from the detector. The imaging detector was a charge-coupled device camera coupled with a scintillator system and $10 \times$ objective lens. The sample was scanned by acquiring 361 projections at equal angles through an angular range of 180 degrees using TXMController software (Xradia Inc.). Each projection image was recorded in
10 seconds. Each image was corrected for the dark current image and for the nonuniform illumination in the imaging system, determined by taking a reference image of the beam without sample. A filtered back projection algorithm was then used to reconstruct the acquisition data to generate a three-dimensional image using TXMReconstructor software (Xradia, Inc.). After the reconstruction process, the distribution of the linear attenuation coefficient was obtained along the section of the sample crossed by the radiation. The total reconstructed volume contained $512 \times 512 \times 512$ voxels, with the voxel size of $4.6 \mu \mathrm{m}^{3}$. Three-dimensional data were computed with TXM3Dviewer software (Xradia, Inc.) and segmented with Avizo software version 6.2 (Visualization Sciences Group/FEI, Hillsboro, OR).

\section{Skull Measurements}

Mice were sacrificed by carbon dioxide asphyxiation. After skin removal, heads were placed in ethanol for 7 days and then in acetone for 7 days. After rinsing in water and 95\% ethanol, samples were stained with $0.015 \%$ (w/v) Alcian Blue, $0.005 \%$ (w/v) Alizarin Red, 5\% (v/v) acetic acid, and 95\% (v/v) ethanol for 10 days. Samples were cleared in $1 \% \mathrm{KOH}$ and $20 \%$ glycerol at $37^{\circ} \mathrm{C}$ for 2 to 3 days, then at room temperature for 2 months. Measurements of skull dimensions, as defined by Richtsmeier et al, ${ }^{27}$ were taken with a J.B.S. $150-\mathrm{mm}$ digital Vernier caliper (VWR International, Murarrie, QLD, Australia), according to the protocol described by Odgren et al. ${ }^{28}$

\section{Hematological Analysis}

Blood was collected from the retro-orbital plexus into Microtainer tubes containing EDTA (BD Biosciences, San Jose, CA). Platelet counts and volumes were determined using an Advia 2120 analyser (Siemens Medical Solutions, Bayswater, VIC, Australia). Megakaryocytes were counted in 10 fields at $\times 200$ magnification per sternum, and the average number of megakaryocytes per field was calculated.

\section{Statistical Analysis}

Platelet counts, megakaryocyte counts, ABR thresholds, and skull measurements were compared using one-way analysis of variance to determine whether there was a significant difference between wild-type, Ets $^{+/-}, \mathrm{Flil}^{+/-}$, and $\mathrm{Ets}^{+/-} \mathrm{Flil}^{+/-}$mice. When a significant difference was found, all genotypes were compared with each other using the Dunnett multiplecomparison test. Statistical tests were performed using Prism 6 for Mac OS X software version 6.0f (GraphPad Software Inc., La Jolla, CA).

\section{Results}

Haploinsufficiency for Fli1 Causes Thrombocytopenia

Ets ${ }^{+/-} \mathrm{Flil}^{+/-}$mice were viable as adults. Unlike Ets ${ }^{+/-}$ littermates, which had normal numbers of platelets in their 

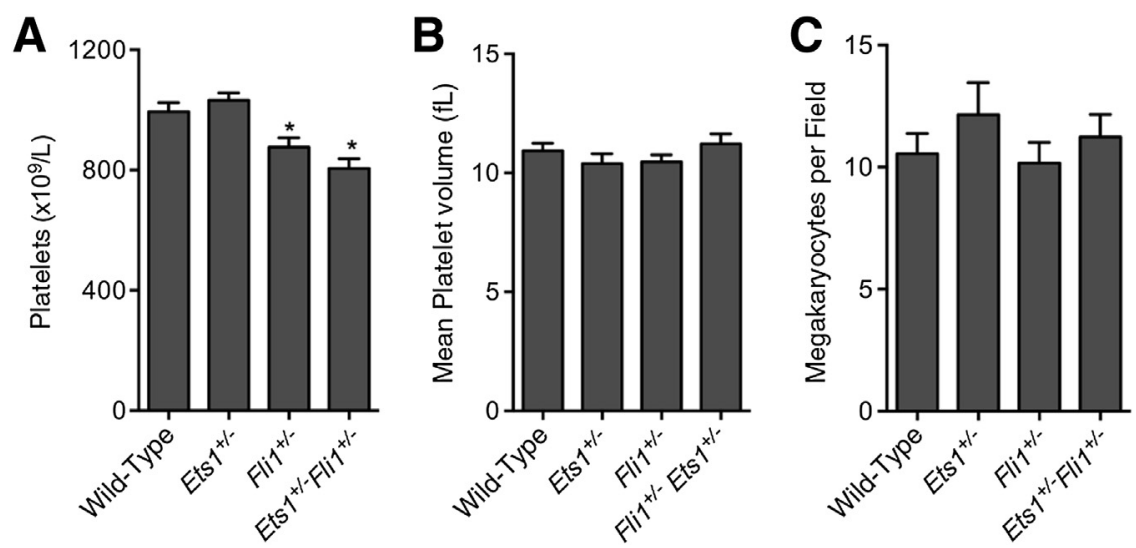

Figure $1 \mathrm{Fli1}^{+/-}$and $\mathrm{Ets} 1^{+/-} \mathrm{Fli1} 1^{+/-}$mice are thrombocytopenic. A: Peripheral blood platelet counts. B: Platelet volumes. C: Sternum megakaryocyte densities. Fli $1^{+/-}$and $E t s 1^{+/-}{ }^{-F i 1^{+/-}}$mice have mild thrombocytopenia but normal platelet volumes and megakaryocyte densities. Data are given as means \pm SEM. $N=22$ to 33 mice per genotype for platelet number and volume; $N=6$ mice per genotype for megakaryocyte density. ${ }^{*} P<0.05$ versus wild type. peripheral blood, $\mathrm{Flil}^{+/-}$and $\mathrm{Etsl}^{+/-} \mathrm{Flil}^{+/-}$mice exhibited mild thrombocytopenia at 8 weeks of age (Figure 1A). There was a $12 \%$ reduction in mean peripheral blood platelet count in $\mathrm{Flil}^{+/-}$mice and a $19 \%$ reduction in $\mathrm{Ets}^{+/-} \mathrm{Flil}^{+/-}$ mice. Mean platelet volume was normal in mice of all genotypes (Figure 1B). To determine whether a reduction in bone marrow megakaryocytes was the cause of thrombocytopenia in $\mathrm{Flil}^{+/-}$and $\mathrm{Ets}^{+/-} \mathrm{Flil}^{+/-}$mice, these cells were examined by light microscopy of sternum sections. Megakaryocytes were present in normal numbers (Figure 1C), and no obvious morphological abnormalities were detected (data not shown).

\section{Fli1 ${ }^{+/-}$and $E t s 1^{+/-} \mathrm{Fli1}^{+/-}$Mice Are Hearing Impaired}

The ABR represents the summation of brain neural activity induced by repeated sound stimuli. The ABR threshold is the quietest stimulus that reproducibly elicits a response and is closely related to the threshold of hearing. ${ }^{29}$ ABRs, induced by mixed-frequency (click) stimuli at 100-dB SPL, were of normal shape and size in $\mathrm{Etsl}^{+/-}, \mathrm{Flil}^{+/-}$, and Ets $1^{+/-} \mathrm{Flil}^{+/-}$mice (Figure 2A). However, the mean click ABR threshold was elevated by $15-\mathrm{dB}$ SPL in $\mathrm{Flil}^{+/-}$mice and 34-dB SPL in Ets ${ }^{+/-}$Flil $^{+/-}$mice (Figure 2B). Hearing impairment was partially penetrant in $\mathrm{Flil}^{+/-}$mice and fully penetrant in Ets $1^{+/-}$Flil $^{+/-}$mice. Mean ABR thresholds to single-frequency stimuli between 4 and 32 $\mathrm{kHz}$ were elevated by 11 - to $16-\mathrm{dB}$ SPL in $\mathrm{Flil}^{+/-}$mice and 25- to 32-dB SPL in EtsI ${ }^{+/-} \mathrm{Flil}^{+/-}$mice (Figure 2C). $E t s 1^{+/-}$mice had normal hearing.

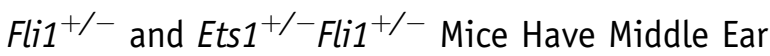 Abnormalities}

We next investigated the pathological basis of the hearing impairment in Flil ${ }^{+/-}$and Ets $1^{+/-} \mathrm{Flil}^{+/-}$mice. Sound is delivered through the middle ear to the inner ear, or cochlea, composed of both osseous and membranous spirals. Within the membranous spiral, sensory hair cells convert sound into electrochemical signals that traverse the auditory nerve upwards to the temporal lobe of the brain. Histological sections through the cochlea were examined by light microscopy to determine whether abnormalities of this structure were responsible for hearing deficits in $\mathrm{Flil}^{+/-}$and $\mathrm{Ets} \mathrm{I}^{+/-} \mathrm{Flil}^{+/-}$mice. No abnormalities were detected in the organ of Corti, containing the sensory hair cells, or in Rosenthal canal, containing the auditory neurons (Figure 3, A, C, E, and $\mathrm{H}$ ). Because the magnitude of hearing impairment in $\mathrm{Flil}^{+/-}$and $\mathrm{Ets}^{+/-} \mathrm{Flil}^{+/-}$mice was consistent with failed transmission of sound through the middle ear, ${ }^{30}$ we next examined this structure (Figure 3, B, D, F, G, I, and J). The MEC in Fli1 ${ }^{+/-}$and Ets $1^{+/-}$Flil $^{+/-}$mice was lined by inflamed epithelium and contained cells with the multilobed nuclei characteristic of granulocytes. This inflammation of the middle ear is known as otitis media and is associated with conductive hearing loss. ${ }^{31}$ This may have been the result of infection or underlying immunological abnormalities. The abnormally small size of the MEC in $\mathrm{Flil}^{+/-}$and Ets $1^{+/-} \mathrm{Flil}^{+/-}$mice (Figure 4, A-D) may have rendered the mice susceptible to otitis media or exacerbated the presentation of this phenotype.

To determine whether $\mathrm{Flil}^{+/-}$and Ets $\mathrm{I}^{+/-} \mathrm{Flil}^{+/-}$ hearing impairment was because of failure of sound transmission by the ossicles, these bones were examined under a dissecting microscope. No abnormalities were observed in the malleus and incus (data not shown). However, the stapes was mildly deformed in $\mathrm{Flil}^{+/-}$mice and severely deformed in Ets $1^{+/-} \mathrm{Flil}^{+/-}$mice (Figure 4, $\mathrm{E}-\mathrm{H})$. The stapes is a stirrup-shaped bone with a head that contacts the incus and a footplate that contacts the oval window of the cochlea. The stapedial artery passes through the central obturator foramen, and the two arms are called the anterior and posterior crura. The stapedial muscle attaches at a protuberance on the posterior crus called the tubercle. The Flil ${ }^{+/-}$stapes had slight thickening of the anterior crus. The Ets ${ }^{+/-} \mathrm{Flil}^{+/-}$stapes was narrow, and the obturator foramen was almost closed. X-ray microcomputed tomography imaging revealed that the stapes footplate did not fit snugly into the oval window of the cochlea in $\mathrm{Flil}^{+/-}$and $\mathrm{Etsl}^{+/-} \mathrm{Flil}^{+/-}$mice (Figure 4, I-L). An abnormally wide black area is visible between the stapes footplate and oval window in these scans. The Ets $1^{+/-}$stapes was normal in its shape and fit into the oval window. These results demonstrate that the stapes is malformed in $\mathrm{Flil}^{+/-}$and 


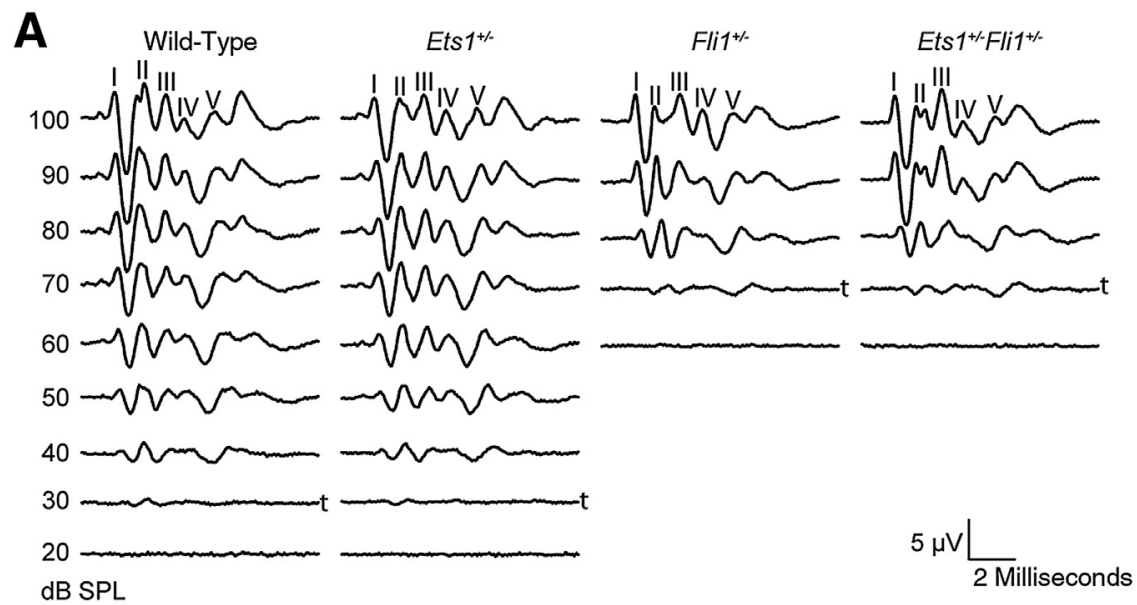

Figure $2 \mathrm{Fli1}^{+/-}$and $\mathrm{Ets} 1^{+/-} \mathrm{Fli1}^{+/-}$mice have hearing impairment. A: Click auditory brainstem responses (ABRs) of wild-type, $E t s 1^{+/-}$, $\mathrm{Fli1}^{+/-}$, and $\mathrm{Ets}^{+/-} \mathrm{Fli1}^{+/-}$mice. The 100-dB sound pressure level (SPL) clicks elicit similar $A B R$ waveforms in mice of all genotypes, with the five principle peaks labeled I to V. Thresholds ( $t$ ), or quietest stimuli that elicit a wave III ABR, are elevated in $\mathrm{Fli1}^{+/-}$and $\mathrm{Ets}^{+/-} \mathrm{Fli1}^{+/-}$mice. B and C: Mean click (B) and single-frequency ABR thresholds (C) are elevated in $\mathrm{Fli1}^{+/-}$mice and further elevated in $\mathrm{Ets}^{+/-} \mathrm{Fli1}^{+/-}$mice. ABR thresholds are statistically different at all frequencies tested. $N=10$ to 11 mice of each genotype at 8 to 10 weeks of age. ${ }^{*} P<0.05$ versus wild type. Horizontal lines in B indicate means. Error bars in C indicate SEM.
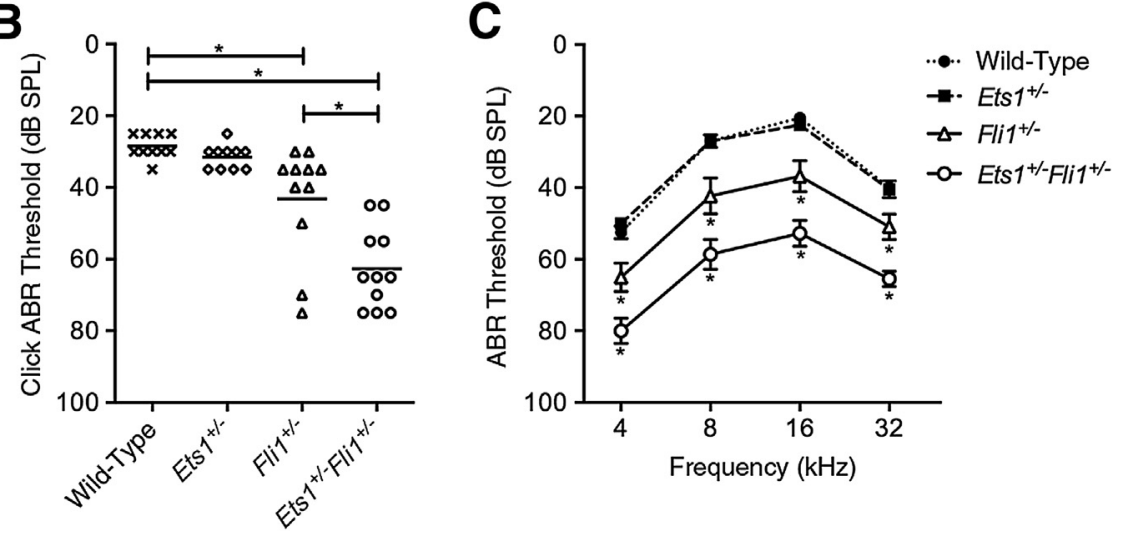

Ets $1^{+/-} \mathrm{Flil}^{+/-}$mice, but do not immediately explain the mechanism of hearing impairment in these mice, because the malformed stapes might still be able to conduct sound to the inner ear.

To determine whether the ossicular chain was able to vibrate unimpeded, the ossicles from one animal of each genotype were imaged in situ using microcomputed tomography. The Ets $1^{+/-}$ossicles were normal, but the Fli $^{+/-}$and Ets $1^{+/-}$Fli $^{+/-}$ossicle chains were fused to the middle ear wall (Figure 4, M-P). The Fli ${ }^{+/-}$incus was fused at a site close to where it articulates with the malleus, whereas the Ets $1^{+/-} \mathrm{Flil}^{+/-}$stapes was fused at the tubercle. These fusions may be related to the small size of the MEC in these mice and would cause conductive hearing loss.

\section{Fli1 $^{+/-}$and Ets $1^{+/-}$Fli1 $^{+/-}$Mice Have a Short Nasal Bone}

Patients with JS have a facial dysmorphism characterized by widely spaced eyes, drooping eyelids, coloboma, downslanting palpebral fissures, epicanthal folds, broad nasal bridge, short nose, small ears, low-set posteriorly rotated ears, and a V-shaped mouth. ${ }^{1}$ We hypothesized that Flil $^{+/-}$ and $E t s 1^{+/-} F l i l^{+/-}$mice may have other craniofacial abnormalities in addition to their small MECs. To assess craniofacial structure in $\mathrm{Flil}^{+/-}$and $\mathrm{Ets}^{+/-} \mathrm{Flil}^{+/-}$mice, Alizarin Red- and Alcian Blue-stained skulls were examined under a dissecting microscope. This revealed that Flil $^{+/-}$and EtsI ${ }^{+/-}$Flil $^{+/-}$mice have abnormally short nasal bones (Figure 5, A-D). Furthermore, coronal sections through the noses of these mice revealed abnormal junction formation between the nasal bone ventral process and the cartilaginous nasal septum (Figure 5, E-H). This distorted the internal dimensions of the nasal cavity, possibly predisposing the mice to otitis media. Through measuring the dimensions of eight skulls of each genotype, we found that Flil $^{+/-}$and Ets $1^{+/-}$Flil $^{+/-}$mice had significantly shorter skulls, noses, nasal bones, and upper jaws than wild-type mice (Figure 5, I-L). Their skull widths, inner canthal distances, and lower jaw lengths were normal (data not shown). There were no statistically significant differences between $\mathrm{Flil}^{+/-}$and $\mathrm{Ets} \mathrm{I}^{+/-} \mathrm{Flil}^{+/-}$skull dimensions.

\section{Discussion}

Contiguous gene deletions in humans often lead to syndromes with characteristic features, revealing roles for the genes within the deleted interval in development and/or particular biological processes. Deletions of human chromosome 11q leading to JS have been well defined, yet the 

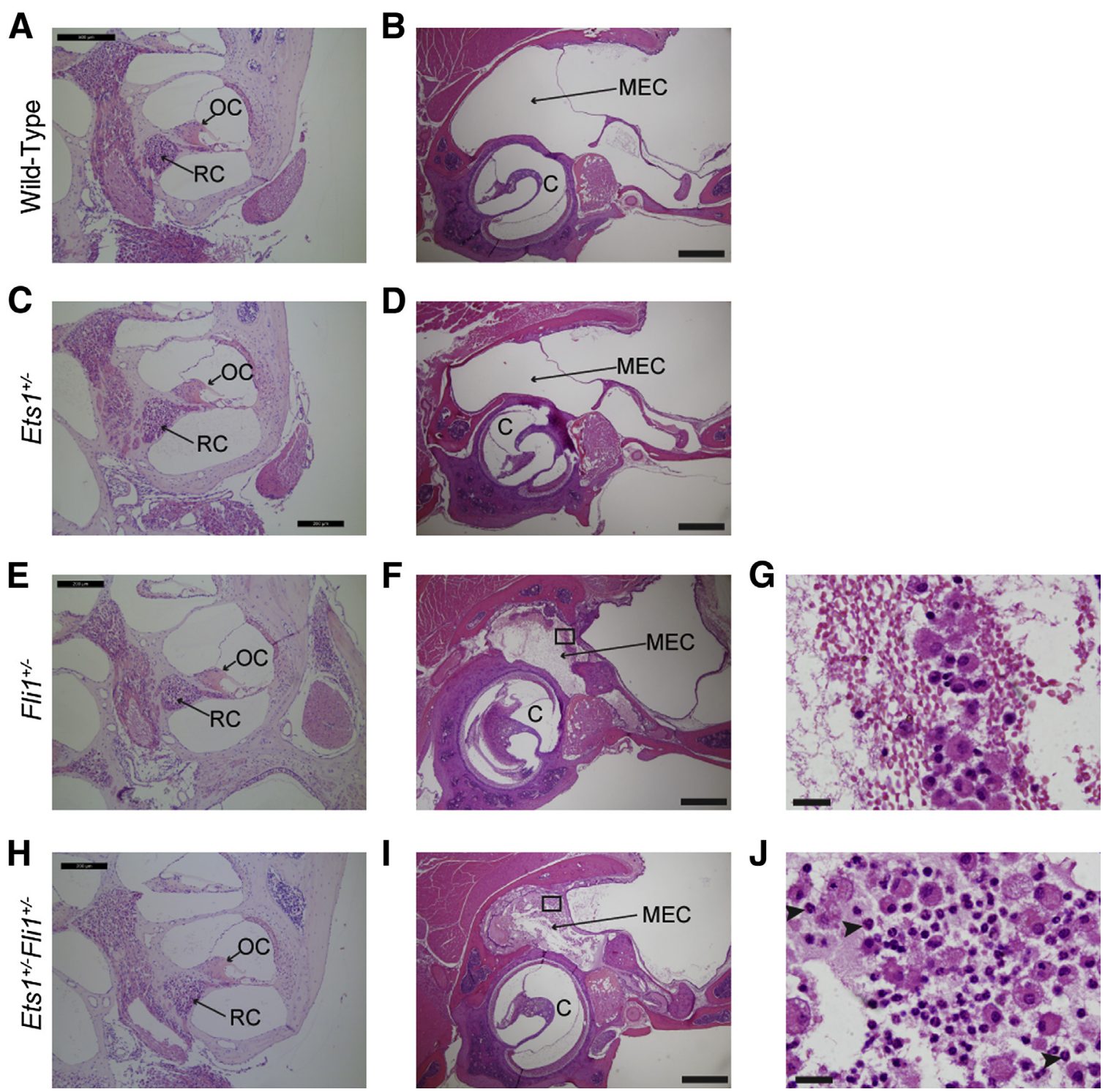

Figure $3 \mathrm{Fli1}^{+/-}$and $\mathrm{Ets} 1^{+/-}$Fli1 ${ }^{+/-}$mice have otitis media. A, C, E, and $\mathbf{H}$ : Midmodiolar sections of middle cochlear turn reveal no abnormalities in the organ of Corti (OC) or Rosenthal canal (RC). B, D, F, and I: Sections through the middle ear cavity (MEC) and cochlea (C) show that Fli $1^{+/-}$and Ets $1^{+/-}$Fli $1^{+/-}$ MECs are lined by inflamed epithelia and contain cells not normally present. $\mathbf{G}$ and $\mathbf{J}$ : Higher-power images of the boxed regions reveal that some of these cells contain multilobed nuclei characteristic of granulocytes (arrowheads). Images are representative of four ears per genotype. A and B: Wild type. C and $\mathbf{D}$ : $\mathrm{Ets}^{+/-}$. E-G: Fli1 ${ }^{+/-}$. H-J: Ets1 $1^{+/-}$Fli1 $^{+/-}$. Scale bars: $200 \mu \mathrm{m}(\mathbf{A}, \mathbf{C}, \mathbf{E}$, and H); $500 \mu \mathrm{m}(\mathbf{B}, \mathbf{D}, \mathbf{F}$, and I); $20 \mu \mathrm{m}(\mathbf{G}$ and J).

contributions of individual genes to particular aspects of this disease are still to be clarified. Herein, we used genetargeted mice to model hemizygous deletion of ETS1 and FLII in JS. In so doing, we identified aspects of JS that can be explained by combined deficiency for these transcription factors and revealed previously undescribed roles for ETS1 and FLI1 in craniofacial development, particularly of the nasal bone, MEC, and ossicles.

Of the characteristic JS phenotypes, thrombocytopenia, short nose, and hearing impairment were recapitulated in Ets ${ }^{+/-} \mathrm{Flil}^{+/-}$mice. Other features of JS, including growth and psychomotor retardation, ocular, immunological, and hormonal problems, and malformations of the heart, kidney, gastrointestinal tract, genitalia, central nervous system, and skeleton, are yet to be fully assessed in the Ets ${ }^{+/-} \mathrm{Flil}^{+/-}$mice, and will serve as the focus of future studies.

\section{Fli1 Haploinsufficiency Causes Thrombocytopenia}

$\mathrm{Flil}^{+/-}$megakaryocytes have a disorganized demarcation membrane system, vacuolization, and fused $\alpha$-granules. ${ }^{14}$ Our results demonstrate that $\mathrm{Flil}^{+/-}$mice are mildly thrombocytopenic. The difference in platelet counts between wild-type and $\mathrm{Flil}^{+/-}$mice is only statistically significant when many mice are tested. This may explain why $\mathrm{Flil}^{+/-}$thrombocytopenia was not detected previously. ${ }^{13,14}$ Defects in megakaryopoiesis are more severe 

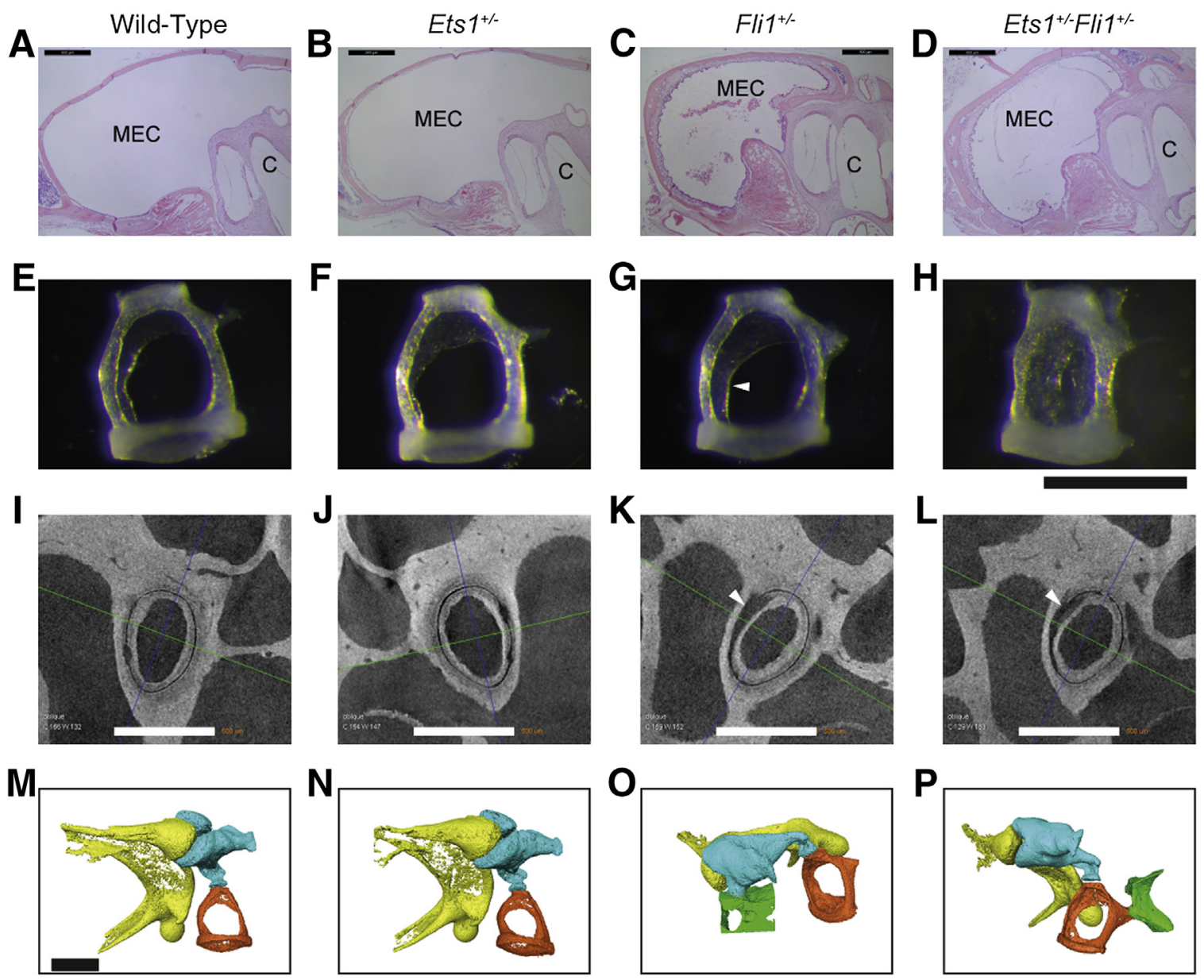

Figure 4 The middle ear is malformed in $\mathrm{Fli1}^{+/-}$and $\mathrm{Ets} 1^{+/-} \mathrm{Fli1} 1^{+/-}$mice. A-D: Light micrographs of hematoxylin and eosin-stained sections through the middle ear cavity (MEC) and cochlea (C). In Fli1 $1^{+/-}$and Ets $1^{+/}$Fli1 $1^{+/-}$mice, the MEC is abnormally small. Images are representative of four ears per genotype. E-H: Light micrographs of the right stapes. The Fli1 ${ }^{+/-}$stapes anterior crus is abnormally wide (arrowhead). The Ets $1^{+/-}$Fli $1^{+/-}$ stapes is narrow, and the obturator foramen is almost closed. Images are representative of eight wild-type, eight Ets $1^{+/-}, 12 \mathrm{Fli1} 1^{+/-}$, and $12 \mathrm{Ets} 1^{+/-}$Fli $1^{+/-}$ stapes. I-L: Microcomputed tomography (MicroCT) cross sections through the stapes footplate and oval window of the cochlea. The Fli $1^{+/-}$and Ets $1^{+/-}$Fli $1^{+/-}$ stapes footplates do not fit snugly, with black space visible between the footplate and the oval window (arrowheads). Images representative of two wild-type, one $\mathrm{Ets} \mathrm{1}^{+/-}$, one $\mathrm{Fli1} 1^{+/-}$, and two Ets $1^{+/-}$Fli1 ${ }^{+/-}$ears. M-P: Segmented X-ray MicroCT images of right ear ossicles with malleus colored yellow; incus, blue; and stapes, orange. The Fli1 ${ }^{+/-}$incus and the Ets $1^{+/-}$Fli1 $1^{+/-}$stapes are fused to the middle ear wall (green). A, E, I, and M: Wild

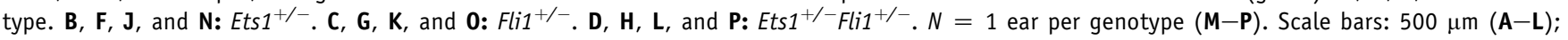
$460 \mu \mathrm{m}(\mathbf{M}-\mathbf{P})$.

in $\mathrm{Erg}^{+/-} \mathrm{Flil}^{+/-}$mice than in $\mathrm{Erg}^{+/-}$or $\mathrm{Flil}^{+/-}$mice, indicating partial functional redundancy of these closely related transcription factors. ${ }^{14}$ In contrast, thrombocytopenia is of equivalent severity in $E t s 1^{+/-} \mathrm{Flil}^{+/-}$and $\mathrm{Flil}^{+/-}$mice. Combined with the observation that $\mathrm{Ets}^{-/-}$ mice have normal platelet counts, ${ }^{16}$ these results indicate that ETS1 is not required for megakaryopoiesis or platelet production. These results support the hypothesis that hemizygosity for FLII causes thrombocytopenia in JS and Paris-Trousseau syndrome ${ }^{3}$ and indicate that hemizygosity for ETS1 is unlikely to contribute to this thrombocytopenia. JS platelets have giant $\boldsymbol{\alpha}$-granules ${ }^{2}$ and are deficient in dense bodies, ${ }^{32}$ and patients with normal platelet counts exhibit prolonged bleeding times, ${ }^{4}$ indicating platelet dysfunction. Platelets from patients heterozygous for FLII mutations are also functionally impaired, with reduced dense granule secretion and impaired aggregation in response to a panel of agonists. ${ }^{33}$ Murine $\mathrm{Flil}^{+--}$platelets have a normal lifespan ${ }^{14}$ and volume (Figure 1), although studies to assess function are yet to be performed.

\section{FLI1 and ETS1 Play Partially Redundant Roles in Auditory Development}

Our work demonstrates that, unlike in the hematopoietic system, FLI1 and ETS1 play partially redundant roles in auditory development. Ets ${ }^{+/-} \mathrm{Flil}^{+/-}$mice display completely penetrant hearing impairment, whereas this phenotype is partially penetrant in $\mathrm{Flil}^{+/-}$mice. Also, Ets $1^{+/-} \mathrm{Flil}^{+/-}$mice display a more severely deformed stapes than $\mathrm{Flil}^{+/-}$mice. Hearing impairment in $\mathrm{Flil}^{+/-}$ 

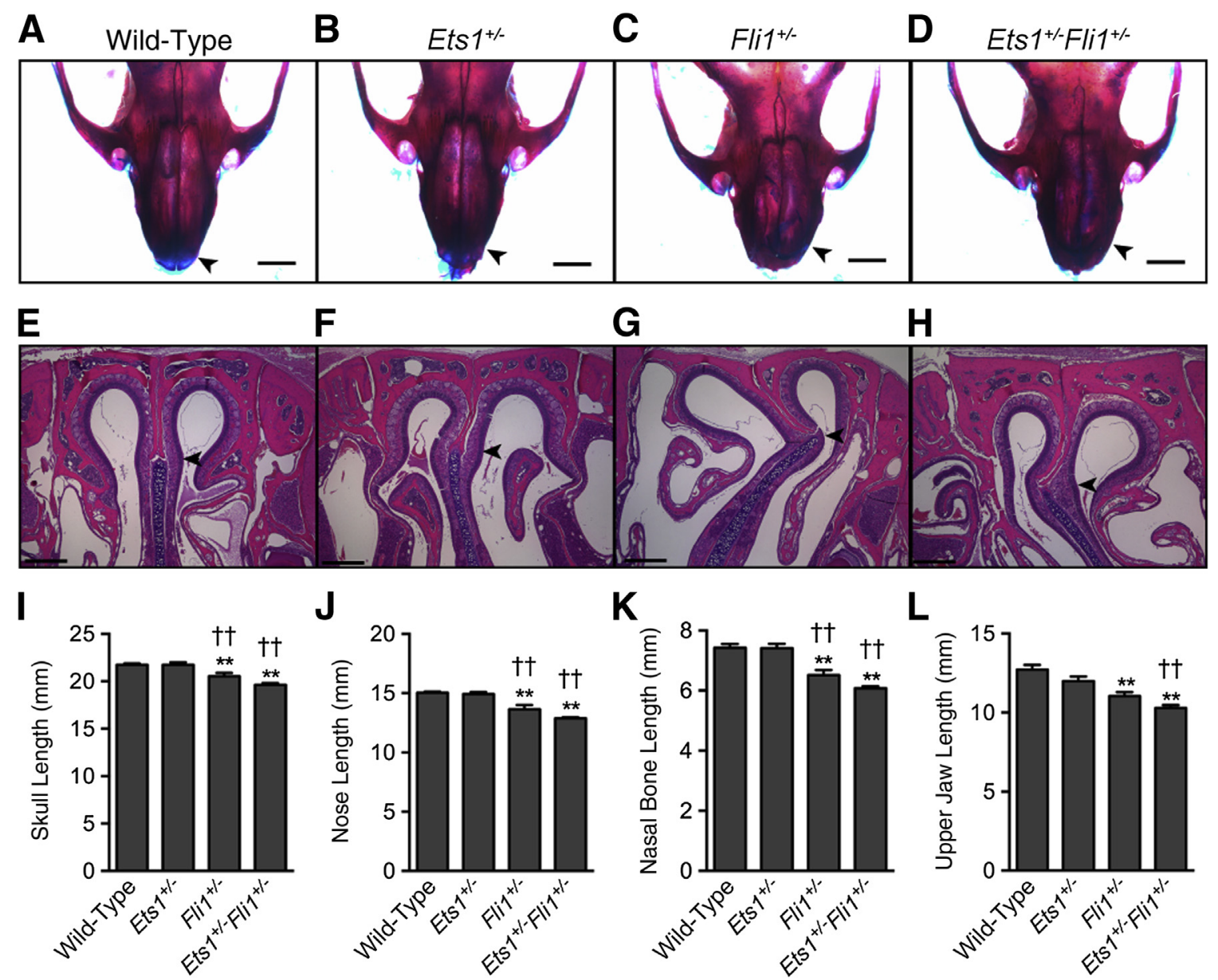

Figure $5 \mathrm{Fli} 1^{+/-}$and $E t s 1^{+/-}$Fli $1^{+/-}$mice have short nasal bones. A-D: Dorsal view of Alizarin Red- and Alcian Blue-stained male mouse skulls with lower jaws removed. The nasal bone (arrowheads) is short in Fli $1^{+/-}$and $E t s 1^{+/-}$Fli $1^{+/}$mice. E-H: Coronal sections through the nasal region of the skull were stained with hematoxylin and eosin and imaged. Arrowheads indicate the point where the nasal bone process (pink) meets the cartilaginous nasal septum (purple). This interface is malformed in Fli $1^{+/-}$and $E t s 1^{+/-}$Fli $1^{+/-}$mice, leading to distortion of the nasal cavity. A and E: Wild type. B and F: Ets $1^{+/-}$. C and G: Fli1 $1^{+/-}$. D and $\mathbf{H}$ : Ets $1^{+/-}$Fli1 ${ }^{+/-}$. I-L: Skull dimensions for four female and four male mice of each genotype at 8 to 10 weeks of age. Fli1 ${ }^{+/-}$and Ets $1^{+/-}$Fli $1^{+/-}$mice have short skulls, noses, nasal bones, and upper jaws. Data are given as means \pm SEM $(\mathbf{I}-\mathbf{L}) .{ }^{*} P<0.01$ versus wild type; ${ }^{\dagger \dagger} P<0.01$ versus Ets ${ }^{+/-}$. Scale bars: $2 \mathrm{~mm}(\mathbf{A}-\mathbf{D})$; $500 \mu \mathrm{m}(\mathbf{E}-\mathbf{H})$.

and $\mathrm{EtsI}^{+/-} \mathrm{Flil}^{+/-}$mice is likely to be conductive, rather than sensorineural, because the middle ear has multiple abnormalities, whereas the cochlea appears normal on gross histological examination. However, we cannot rule out some degree of sensorineural involvement without more detailed analysis of the cochlea. The MEC epithelium is inflamed, and granulocytes are present. This may indicate that an immune response has been mounted against infection or may be because of underlying immunological abnormalities. The small size of the MEC may impede drainage through the Eustachian tube, leading to otitis media. Alternatively, the malformed interface between the nasal bone process and cartilaginous nasal septum and distortion of the nasal cavity may predispose to otitis media. The ossicles are sometimes fused to the middle ear wall, the stapes is deformed, and the stapes footplate does not fit snugly into the oval window of the cochlea. In wild-type mice, fixation of the ossicles to the middle ear wall causes a 12- to 25-dB SPL hearing loss, ${ }^{30}$ which is of similar magnitude to the 11- to 34-dB SPL hearing impairment in $\mathrm{Flil}^{+/-}$and $\mathrm{Etsl}^{+/-} \mathrm{Flil}^{+/-}$mice. Thus, conductive hearing impairment could arise because of ossicle fixation, stapes malformation, otitis media, or a combination of factors.

\section{Hearing Impairment in JS Is Likely the Result of Hemizygosity for ETS1 and FLI1}

Hearing impairment in JS has previously been ascribed to hemizygosity for TECTA, ${ }^{1}$ which encodes a component of the tectorial membrane in the cochlea. ${ }^{34}$ However, hearing impairment has been reported in six JS patients, with deletion breakpoints telomeric to TECTA but centromeric to ETS1 and FLII. ${ }^{35-38}$ Furthermore, a splice site mutation in TECTA is associated with recessive deafness and is predicted to cause premature termination of protein translation, ${ }^{39}$ whereas missense mutations in TECTA cause dominant deafness. ${ }^{40}$ These single amino acid substitutions may act in a 
dominant-negative manner by disrupting interactions between tectorin polypeptides. $^{39}$ In mice, mutations encoding the orthologous p.Y1870C and p.C1509G substitutions are also dominant, $^{41,42}$ whereas a Tecta-null allele causes recessive, sensorineural deafness with tectorial membrane pathology. ${ }^{43}$ The recessive mode of inheritance and sensorineural basis of the deafness associated with the null allele in mice indicate that hearing impairment in JS is unlikely to be because of hemizygosity for TECTA. The dominant mode of inheritance and otitis media associated with ETS1 and FLI1 deficiency in mice indicate that hearing impairment in JS is likely the result of hemizygosity for ETS1 and FLII.

\section{Fli1 ${ }^{+/-}$and $E t s 1^{+/-}$Fli1 ${ }^{+/-}$Mice Exhibit Disrupted Craniofacial Development}

The short nasal bone in $\mathrm{Flil}^{+/-}$and $\mathrm{Ets}^{+/-} \mathrm{Flil}^{+/-}$mice is likely to have the same etiology as the short nose in JS patients. ${ }^{1}$ However, unlike JS patients, who have widely spaced eyes, inner canthal distance is normal in $\mathrm{Flil}^{+/-}$and $\mathrm{Ets} \mathrm{I}^{+/-} \mathrm{Flil}^{+/-}$ mice. Thus, not all aspects of JS facial dysmorphism are recapitulated in $\mathrm{Flil}^{+/-}$and $\mathrm{Ets} \mathrm{I}^{+/-} \mathrm{Flil}^{+/-}$mice. This may indicate that other hemizygous genes in JS, such as BARX2, ${ }^{44}$ contribute to facial dysmorphism. During embryonic development, neural crest cells migrate to the frontonasal process and branchial arches (BAs), where they form the bones of the skull. ${ }^{45}$ Flil and Etsl are expressed in neural crest cells at this stage. ${ }^{11,12,18}$ The nasal bone and premaxillary bone of the upper jaw develop in the frontonasal process, whereas the maxillary and jugal bones of the upper jaw, malleus, and incus develop in BA1. ${ }^{45}$ The MEC develops from the first brachial pouch, and the stapes develops in BA2. ${ }^{46} \mathrm{Ets}^{+/-}$mice have a white belly spot, ${ }^{18}$ indicating a defect in neural crest-derived melanocyte progenitors. ${ }^{47}$ These observations indicate that the craniofacial and middle ear abnormalities in $\mathrm{Flil}^{+/-}$and $\mathrm{Ets}^{+/-} \mathrm{Flil}^{+/-}$may derive from abnormal migration, proliferation, or differentiation of neural crest cells in the frontonasal process, BA1, and BA.

In summary, we have demonstrated that FLI1 and ETS1 play partially redundant roles in craniofacial development, particularly of the nose, MEC, and ossicles. The severity of hearing impairment in $\mathrm{Flil}^{+/-}$and $\mathrm{Etsl}^{+/-} \mathrm{Flil}^{+/-}$mice is consistent with conductive loss. The ossicle defects, otitis media, or both could cause conductive hearing loss. The short nasal bone and malformed nasal septum may increase susceptibility to otitis media. Our study also demonstrates the utility of using mice haploinsufficient for multiple genes to model a contiguous gene deletion disorder. The phenotype of the Ets $1^{+/-} \mathrm{Flil}^{+/-}$mouse indicates that hearing impairment of JS patients is likely to be caused by hemizygosity for FLII and ETS1, and resultant malformation and inflammation of the middle ear.

\section{References}

1. Mattina T, Perrotta CS, Grossfeld P: Jacobsen syndrome. Orphanet J Rare Dis 2009, 4:9
2. Krishnamurti L, Neglia JP, Nagarajan R, Berry SA, Lohr J, Hirsch B, White JG: Paris-Trousseau syndrome platelets in a child with Jacobsen's syndrome. Am J Hematol 2001, 66:295-299

3. Favier R, Jondeau K, Boutard P, Grossfeld P, Reinert P, Jones C, Bertoni F, Cramer EM: Paris-Trousseau syndrome: clinical, hematological, molecular data of ten new cases. Thromb Haemost 2003, 90:893-897

4. Grossfeld PD, Mattina T, Lai Z, Favier R, Jones KL, Cotter F, Jones C: The $11 \mathrm{q}$ terminal deletion disorder: a prospective study of 110 cases. Am J Med Genet A 2004, 129A:51-61

5. Hollenhorst PC, McIntosh LP, Graves BJ: Genomic and biochemical insights into the specificity of ETS transcription factors. Annu Rev Biochem 2011, 80:437-471

6. Nunn MF, Seeburg PH, Moscovici C, Duesberg PH: Tripartite structure of the avian erythroblastosis virus E26 transforming gene. Nature 1983, 306:391-395

7. Leprince D, Gegonne A, Coll J, de Taisne C, Schneeberger A, Lagrou C, Stehelin D: A putative second cell-derived oncogene of the avian leukaemia retrovirus E26. Nature 1983, 306:395-397

8. Watson DK, McWilliams MJ, Lapis P, Lautenberger JA, Schweinfest CW, Papas TS: Mammalian ets-1 and ets-2 genes encode highly conserved proteins. Proc Natl Acad Sci U S A 1988, 85:7862-7866

9. Ben-David Y, Giddens EB, Bernstein A: Identification and mapping of a common proviral integration site Fli-1 in erythroleukemia cells induced by Friend murine leukemia virus. Proc Natl Acad Sci U S A 1990, 87:1332-1336

10. Ben-David Y, Giddens EB, Letwin K, Bernstein A: Erythroleukemia induction by Friend murine leukemia virus: insertional activation of a new member of the ets gene family, Fli-1, closely linked to c-ets-1. Genes Dev 1991, 5:908-918

11. Kola I, Brookes S, Green AR, Garber R, Tymms M, Papas TS, Seth A: The Ets1 transcription factor is widely expressed during murine embryo development and is associated with mesodermal cells involved in morphogenetic processes such as organ formation. Proc Natl Acad Sci U S A 1993, 90:7588-7592

12. Melet F, Motro B, Rossi DJ, Zhang L, Bernstein A: Generation of a novel Fli-1 protein by gene targeting leads to a defect in thymus development and a delay in Friend virus-induced erythroleukemia. Mol Cell Biol 1996, 16:2708-2718

13. Hart A, Melet F, Grossfeld P, Chien K, Jones C, Tunnacliffe A, Favier R, Bernstein A: Fli-1 is required for murine vascular and megakaryocytic development and is hemizygously deleted in patients with thrombocytopenia. Immunity 2000, 13:167-177

14. Kruse EA, Loughran SJ, Baldwin TM, Josefsson EC, Ellis S, Watson DK, Nurden P, Metcalf D, Hilton DJ, Alexander WS, Kile BT: Dual requirement for the ETS transcription factors Fli-1 and Erg in hematopoietic stem cells and the megakaryocyte lineage. Proc Natl Acad Sci U S A 2009, 106:13814-13819

15. Raslova H, Komura E, Le Couedic JP, Larbret F, Debili N, Feunteun J, Danos O, Albagli O, Vainchenker W, Favier R: FLI1 monoallelic expression combined with its hemizygous loss underlies ParisTrousseau/Jacobsen thrombopenia. J Clin Invest 2004, 114:77-84

16. Barton K, Muthusamy N, Fischer C, Ting CN, Walunas TL, Lanier LL, Leiden JM: The Ets-1 transcription factor is required for the development of natural killer cells in mice. Immunity 1998, 9:555-563

17. Eyquem S, Chemin K, Fasseu M, Bories JC: The Ets-1 transcription factor is required for complete pre-T cell receptor function and allelic exclusion at the T cell receptor beta locus. Proc Natl Acad Sci U S A 2004, 101:15712-15717

18. Ye M, Coldren C, Liang X, Mattina T, Goldmuntz E, Benson DW, Ivy D, Perryman MB, Garrett-Sinha LA, Grossfeld P: Deletion of ETS1 , a gene in the Jacobsen syndrome critical region, causes ventricular septal defects and abnormal ventricular morphology in mice. Hum Mol Genet 2010, 19:648-656

19. Bories JC, Willerford DM, Grevin D, Davidson L, Camus A, Martin P, Stehelin D, Alt FW: Increased T-cell apoptosis and terminal B-cell differentiation induced by inactivation of the Ets-1 proto-oncogene. Nature 1995, 377:635-638 
20. Spyropoulos DD, Pharr PN, Lavenburg KR, Jackers P, Papas TS, Ogawa M, Watson DK: Hemorrhage, impaired hematopoiesis, and lethality in mouse embryos carrying a targeted disruption of the Fli1 transcription factor. Mol Cell Biol 2000, 20:5643-5652

21. Noben-Trauth K, Zheng QY, Johnson KR: Association of cadherin 23 with polygenic inheritance and genetic modification of sensorineural hearing loss. Nat Genet 2003, 35:21-23

22. Zheng QY, Johnson KR, Erway LC: Assessment of hearing in 80 inbred strains of mice by ABR threshold analyses. Hear Res 1999, 130: 94-107

23. Carpinelli MR, Voss AK, Manning MG, Perera AA, Cooray AA, Kile BT, Burt RA: A new mouse model of Canavan leukodystrophy displays hearing impairment due to central nervous system dysmyelination. Dis Model Mech 2014, 7:649-657

24. Ogier JM, Carpinelli MR, Arhatari BD, Symons RC, Kile BT, Burt RA: CHD7 deficiency in "Looper", a new mouse model of CHARGE syndrome, results in ossicle malformation, otosclerosis and hearing impairment. PLoS One 2014, 9:e97559

25. Carpinelli MR, Wise AK, Arhatari BD, Bouillet P, Manji SS, Manning MG, Cooray AA, Burt RA: Anti-apoptotic gene Bcl2 is required for stapes development and hearing. Cell Death Dis 2012, 3: e362

26. Carpinelli MR, Manning MG, Kile BT, Burt RA: Two ENU-induced alleles of Atp2b2 cause deafness in mice. PLoS One 2013, 8:e67479

27. Richtsmeier JT, Baxter LL, Reeves RH: Parallels of craniofacial maldevelopment in Down syndrome and Ts65Dn mice. Dev Dyn 2000, 217:137-145

28. Odgren PR, Pratt CH, MacKay CA, Mason-Savas A, Curtain M, Shopland L, Ichicki T, Sundberg JP, Donahue LR: Disheveled hair and ear (Dhe), a spontaneous mouse Lmna mutation modeling human laminopathies. PLoS One 2010, 5:e9959

29. Willott JF: Measurement of the auditory brainstem response (ABR) to study auditory sensitivity in mice. Curr Protoc Neurosci 2006, Chapter 8:Unit8 21B

30. Qin Z, Wood M, Rosowski JJ: Measurement of conductive hearing loss in mice. Hear Res 2010, 263:93-103

31. Li JD, Hermansson A, Ryan AF, Bakaletz LO, Brown SD, Cheeseman MT, Juhn SK, Jung TT, Lim DJ, Lim JH, Lin J, Moon SK, Post JC: Panel 4: recent advances in otitis media in molecular biology, biochemistry, genetics, and animal models. Otolaryngol Head Neck Surg 2013, 148:E52-E63

32. White JG: Platelet storage pool deficiency in Jacobsen syndrome. Platelets 2007, 18:522-527

33. Stockley J, Morgan NV, Bem D, Lowe GC, Lordkipanidze M, Dawood B, Simpson MA, Macfarlane K, Horner K, Leo VC, Talks K, Motwani J, Wilde JT, Collins PW, Makris M, Watson SP, Daly ME: Enrichment of FLI1 and RUNX1 mutations in families with excessive bleeding and platelet dense granule secretion defects. Blood 2013, 122 : 4090-4093

34. Legan PK, Rau A, Keen JN, Richardson GP: The mouse tectorins: modular matrix proteins of the inner ear homologous to components of the sperm-egg adhesion system. J Biol Chem 1997, 272:8791-8801
35. Giampietro PF, Babu D, Zabel CA, Silberman T, Zador I, DeBauche D, Ravnan JB, Dave BJ: Novel clinical features in a child with partial deletion of chromosome 11 [del(11)(q24.2)]: further evidence for phenotypic heterogeneity. Am J Med Genet A 2006, 140: 385-387

36. Neavel CB, Soukup S: Deletion of (11)(q24.2) in a mother and daughter with similar phenotypes. Am J Med Genet 1994, 53:321-324

37. Zahn S, Ehrbrecht A, Bosse K, Kalscheuer V, Propping P, Schwanitz G, Albrecht B, Engels H: Further delineation of the phenotype maps for partial trisomy 16q24 and Jacobsen syndrome by a subtle familial translocation $\mathrm{t}(11 ; 16)(\mathrm{q} 24.2 ; \mathrm{q} 24.1)$. Am J Med Genet A 2005, 139:19-24

38. Pivnick EK, Velagaleti GV, Wilroy RS, Smith ME, Rose SR, Tipton RE, Tharapel AT: Jacobsen syndrome: report of a patient with severe eye anomalies, growth hormone deficiency, and hypothyroidism associated with deletion 11 (q23q25) and review of 52 cases. J Med Genet 1996, 33:772-778

39. Mustapha M, Weil D, Chardenoux S, Elias S, El-Zir E, Beckmann JS, Loiselet J, Petit C: An alpha-tectorin gene defect causes a newly identified autosomal recessive form of sensorineural pre-lingual non-syndromic deafness, DFNB21. Hum Mol Genet $1999,8: 409-412$

40. Verhoeven K, Van Laer L, Kirschhofer K, Legan PK, Hughes DC, Schatteman I, Verstreken M, Van Hauwe P, Coucke P, Chen A, Smith RJ, Somers T, Offeciers FE, Van de Heyning P, Richardson GP, Wachtler F, Kimberling WJ, Willems PJ, Govaerts PJ, Van Camp G: Mutations in the human alpha-tectorin gene cause autosomal dominant non-syndromic hearing impairment. Nat Genet 1998, 19:60-62

41. Legan PK, Lukashkina VA, Goodyear RJ, Lukashkin AN, Verhoeven K, Van Camp G, Russell IJ, Richardson GP: A deafness mutation isolates a second role for the tectorial membrane in hearing. Nat Neurosci 2005, 8:1035-1042

42. Xia A, Gao SS, Yuan T, Osborn A, Bress A, Pfister M, Maricich SM, Pereira FA, Oghalai JS: Deficient forward transduction and enhanced reverse transduction in the alpha tectorin $\mathrm{C} 1509 \mathrm{G}$ human hearing loss mutation. Dis Model Mech 2010, 3:209-223

43. Legan PK, Lukashkina VA, Goodyear RJ, Kossi M, Russell IJ, Richardson GP: A targeted deletion in alpha-tectorin reveals that the tectorial membrane is required for the gain and timing of cochlear feedback. Neuron 2000, 28:273-285

44. Krasner A, Wallace L, Thiagalingam A, Jones C, Lengauer C, Minahan L, Ma Y, Kalikin L, Feinberg AP, Jabs EW, Tunnacliffe A, Baylin SB, Ball DW, Nelkin BD: Cloning and chromosomal localization of the human BARX2 homeobox protein gene. Gene 2000, 250: $171-180$

45. Santagati F, Rijli FM: Cranial neural crest and the building of the vertebrate head. Nat Rev Neurosci 2003, 4:806-818

46. Mallo M: Formation of the outer and middle ear, molecular mechanisms. Curr Top Dev Biol 2003, 57:85-113

47. Bonaventure J, Domingues MJ, Larue L: Cellular and molecular mechanisms controlling the migration of melanocytes and melanoma cells. Pigment Cell Melanoma Res 2013, 26:316-325 